\title{
Power Translations for Deterrence or Stimulation of Wheelie/Wheel-stand for a Straight Moving Vehicle
}

\author{
Gursagar Singh \\ Mechanical Engineering Department, Thapar Institute of Engineering and Technology, India
}

\begin{abstract}
The objective of this paper is to identify and study various factors which induce the possibility of wheelie/wheel-stand of a rear wheel drive vehicle. The purpose is to assist race and stunt drivers with a mathematical indicator (M) which could predict if a vehicle will undergo a wheel-stand or not, and if it will, what are the safe limits to avoid rollover and loss of control. The principle idea behind this research is that during a wheelie, the total power [P] supplied by an engine is utilized in uplifting [P1] and manoeuvring [P2] of the vehicle. After determining the coordinates of centre of gravity of the vehicle, $\mathrm{P} 1$ and $\mathrm{P} 2$ are calculated and on the basis of these values, factor of power translation $[\mathrm{M}]$ is calculated.
\end{abstract}

\section{INTRODUCTION}

We all have seen vehicles saluting up at some point of our life, may it be in a drag racing event or a stunt show on internet or TV, wheelies are always a pleasure to watch. For a normal person, who has nothing to do with automobile tech and who has no interest in physics or mechanics will only see a wheelie as front tire off the ground with roar of the high-power engine. But in actual a wheelie is not as simple as it seems. Various force equilibriums are broken during a wheel stand to make the vehicle ride on its rear rotor.

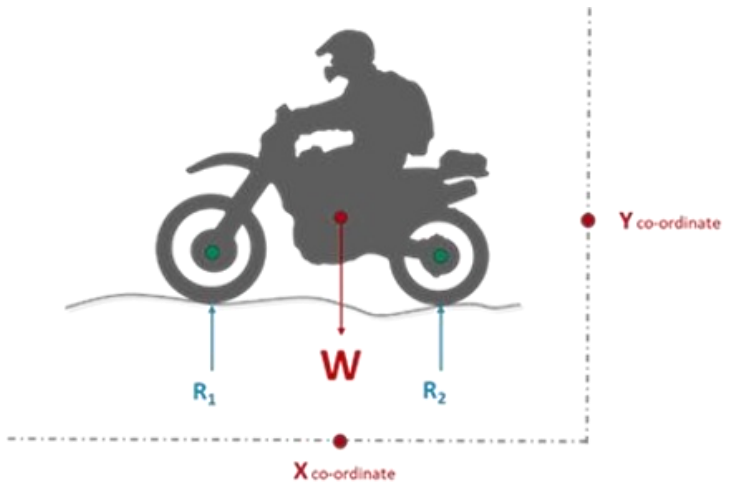

Figure 1(a). Weight and reaction forces.

$\mathrm{W}=$ Weight of vehicle in newtons

$\mathrm{R}_{1}=$ Reaction force at front wheel(s) in newtons

$\mathrm{R}_{2}=$ Reaction force on rear wheel(s) in newtons

Let us consider a motorbike.

The whole weight of this two-wheeler will act on its point of Center of Gravity (CG), which lies somewhere between the $\mathrm{X}$-co-ordinates and $\mathrm{Y}$ - co-ordinates if viewed from side of the motorbike. In this case the co-ordinates of $\mathrm{CG}$ in $\mathrm{Z}$ direction have been ignored because it will not be needed in further calculations. The front and the rear wheels experience reaction forces, combinely equivalent to weight. In order to undergo a wheelie or wheel stand the torque of the rear wheel must be equivalent to moment generated by weight vector on the center of rear wheel.

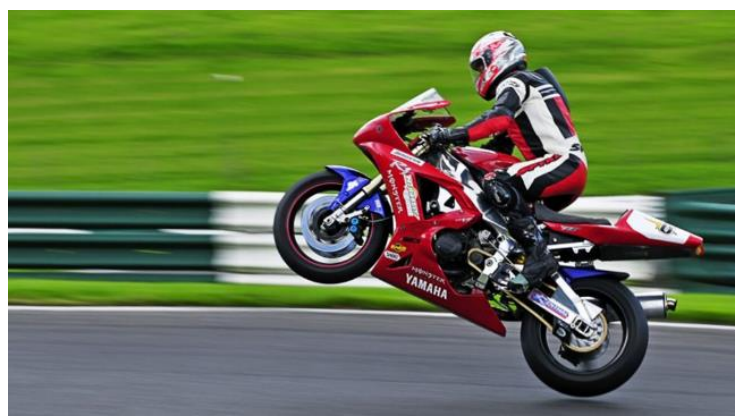

Figure 1(b). A two-wheeler undergoing a wheel-stand

\section{TO FIND CG OF THE VEHICLE}

As mentioned previously, for calculations on moments and torques, it is required that $\mathrm{CG}$ of the undertaken fourwheeler or two-wheeler vehicle must be known. For cars and other four wheelers it is has been assumed that their $\mathrm{CG}$ point is known. Moreover, the reactions at various tires of a four-wheeler must also be known to apply this theory. It is quite interesting to note that the point of CG of any two-wheeler can be found out with the help of some known dimensions. For this, the following assumptions and considerations must be made:

1. The CG co-ordinate in $\mathrm{Y}$ direction lies on the axis $\mathrm{AB}$ which adjoins rotation centres for both wheels. 
2. The total weight $\mathrm{W}$ includes the weight of rider as well.

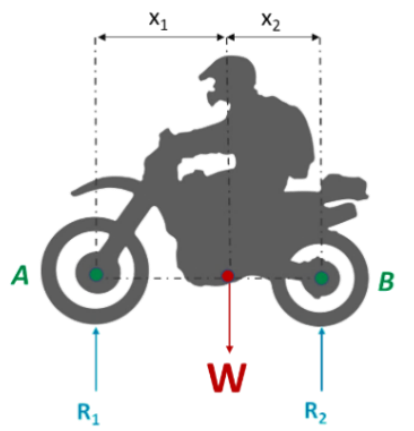

Figure 1(c). Axis AB adjoining rotation centres of both wheels.

\subsection{CG co-ordinates along $X$-axis:}

Let $\mathrm{x}_{1}$ and $\mathrm{x}_{2}$ be distances of point of $\mathrm{CG}$ from $\mathrm{A}$ and $\mathrm{B}$ respectively.

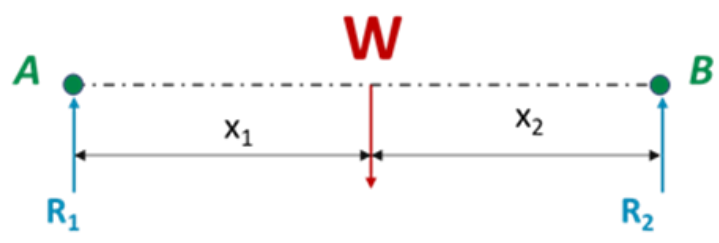

Figure 2. Axis $A B$ adjoining rotation centres of both wheels.

Taking Moments about B,

As we know,

$$
\begin{aligned}
& \mathrm{R}_{1}\left(\mathrm{x}_{1}+\mathrm{x}_{2}\right)=\mathrm{Wx}_{2} \\
& \mathrm{R}_{1}=\mathrm{Wx}_{2} /\left(\mathrm{x}_{1}+\mathrm{x}_{2}\right)^{[1][2][3]}
\end{aligned}
$$

$$
\mathrm{R}_{1}+\mathrm{R}_{2}=\mathrm{W}
$$$$
\mathrm{R}_{2}=\mathrm{W}-\mathrm{R}_{1}{ }^{[1][2][3]}
$$

So $\mathrm{R}_{1}$ and $\mathrm{R}_{2}$ can be found if $\mathrm{W}, \mathrm{x}_{1}$ and $\mathrm{x}_{2}$ are known.

From fig. 2 it can be noted that,

$$
\begin{array}{ll}
\mathrm{R}_{1}+\mathrm{R}_{2}=\mathrm{W} & -(\text { Eq. } 1) \\
\mathrm{x}_{1}+\mathrm{x}_{2}=\mathrm{AB} & -(\text { Eq. } 2) \\
\mathrm{R}_{1} \mathrm{x}_{1}=\mathrm{R}_{2} \mathrm{X}_{2} & -(\text { Eq.3) }
\end{array}
$$

From eq. (1), (2) and (3),

$$
\begin{aligned}
& \mathrm{x}_{1}=A B-\mathrm{x}_{2} \\
& \mathrm{R}_{1}\left(A B-\mathrm{x}_{2}\right)-\mathrm{R}_{2} \mathrm{X}_{2}=0 \\
& \mathrm{R}_{1} A B-\mathrm{R}_{1} \mathrm{x}_{2}-\mathrm{R}_{2} \mathrm{x}_{2}=0 \\
& \mathrm{R}_{1} A B=\mathrm{R}_{1} \mathrm{x}_{2}-\mathrm{R}_{2} \mathrm{x}_{2} \\
& \mathrm{R}_{1} \mathrm{AB}=\mathrm{x}_{2}\left(\mathrm{R}_{1}+\mathrm{R}_{2}\right) \\
& \mathrm{R}_{1} \mathrm{AB} /\left(\mathrm{R}_{1}+\mathrm{R}_{2}\right)=\mathrm{x}_{2}
\end{aligned}
$$

So $\mathbf{x}$, the $\mathrm{CG}$ co-ordinate along $\mathrm{X}$-axis is $=$

$$
\mathbf{R}_{1} \mathbf{A B} /\left(\mathbf{R}_{1}+\mathbf{R}_{2}\right)
$$

\subsection{CG co-ordinates along Y-axis:}

Let us now consider the motorbike is tilted at an angle $\theta$, such that the front wheel is lifted ' $\mathrm{P}$ ' distance from ground. In order to find the coordinates along $\mathrm{Y}$-axis we will have to repudiate the assumption ${ }^{1}$ made in 1.2.1 (The CG coordinate in $\mathrm{Y}$ direction lies on the axis $\mathrm{AB}$ which adjoins rotation centers for both wheels), because in actual scenario the point of $\mathrm{CG}$ will always lie above the $\mathrm{AB}$ axis.

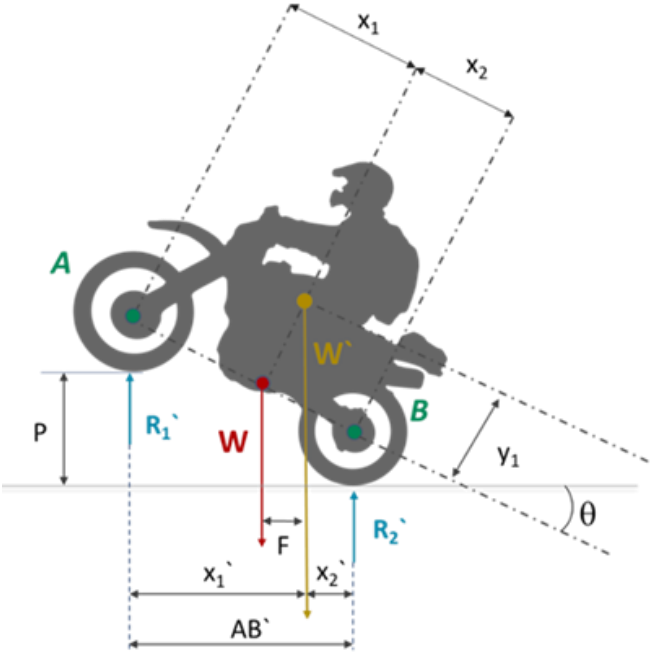

Figure 3. Various forces when the motorbike is tilted at an angle $\theta$.

Referring to fig. 3

$\mathrm{W}^{`}=\mathrm{W}=$ Weight of motorbike

$\mathrm{R}_{1}{ }^{`}=$ Reaction force due to weight at front wheel while the vehicle is tilted.

$\mathrm{R}_{2}{ }^{`}=$ Reaction force due to weight at rear wheel while the vehicle is tilted.

$\mathrm{x}_{1}, \mathrm{x}_{2}=\mathrm{Co}$-ordinates of CG along $\mathrm{X}$-axis (when the bike was not tilted).

$\mathrm{x}_{1}{ }^{\prime}, \mathrm{x}_{2}{ }^{\prime}=$ Apparent co-ordinates of $\mathrm{CG}$ along $\mathrm{X}$-axis (when the bike was tilted).

$\mathrm{y}_{1}=$ Co-ordinates of CG along Y-axis.

Applying equation (4) on fig. 3,

We will get,

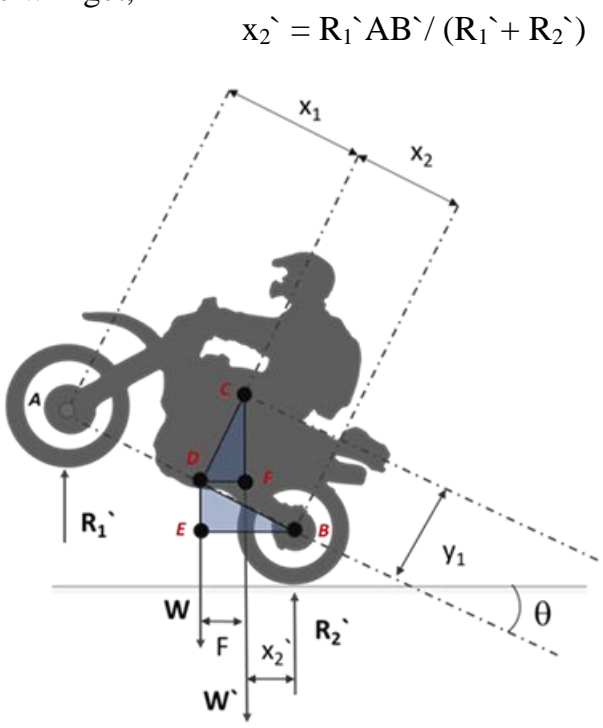

Figure 4(a). $\triangle \mathrm{DEB}$ and $\triangle \mathrm{DCF}$ on bike

Referring to fig. 4(b),

In $\triangle D E B$,

$$
\begin{aligned}
& \mathrm{DB}=\mathrm{x}_{2} \\
& \mathrm{~EB}=\mathrm{x}_{2} \operatorname{Cos} \theta \\
& \mathrm{x}_{2} \operatorname{Cos} \theta-\mathrm{x}_{2}^{\prime}=\mathrm{F}
\end{aligned}
$$




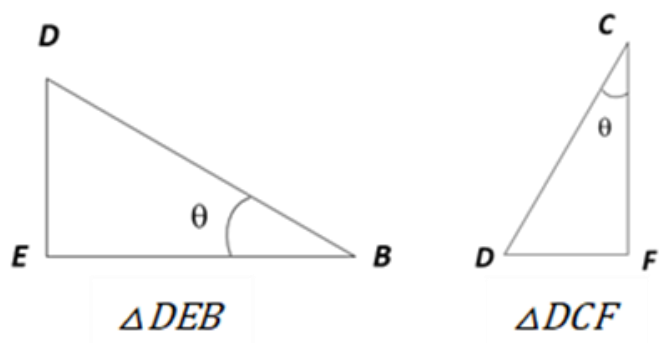

Figure 4(b). $\triangle \mathrm{DEB}$ and $\triangle \mathrm{DCF}$

In $\triangle D C F$,

$$
\begin{aligned}
& \mathrm{DF}=\mathrm{F} \\
& \mathrm{CD}=\mathrm{y}_{1} \\
& \mathrm{y}_{1}=\mathrm{F} / \mathrm{Sin} \theta
\end{aligned}
$$

So $\mathrm{y}_{1}$, the $\mathrm{CG}$ co-ordinate along $\mathrm{Y}$-axis is $=\mathbf{F} / \mathbf{S i n} \boldsymbol{\theta}$

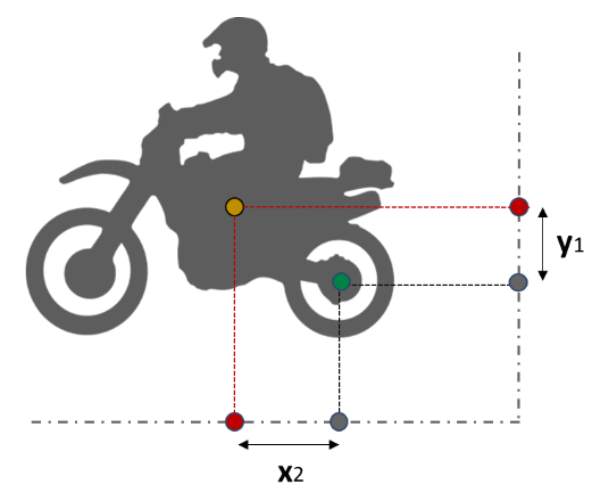

Figure 5. Position of Centre of gravity with reference to rear wheel axle.

\section{POWER TRANSLATIONS IN A WHEEL-STAND}

\subsection{Understanding the physics behind the wheel stand:}

When a vehicle is in the state of rest, it isn't possible for such vehicle to reach some positive value of final velocity in an instant. If this happens then the acceleration of the vehicle will be infinite. ${ }^{[4]}$ The inertia of rest opposes quick movement of vehicle, thus in actual practice it is not possible to attain infinite acceleration.

In case of obnoxious or undesired wheel-stand/wheelie, a highly powerful vehicle engine tends to quickly accelerate the vehicle from rest. The vehicle simply fails to completely overcome its inertia of rest and the torque supplied to wheels results in uplift from the front. But as the vehicle maneuver and start gaining velocity the power supplied by engine redirects itself from the state of wheel stand to desired state of motion.

So, it can be said that the overall scenario is about translation of power. The total power (P) generated by engine is divided into two work streams:

a) Power utilized in uplifting of vehicle, $\mathbf{P}_{\mathbf{1}}$

b) Power utilized in forward motion of the vehicle, $\mathbf{P}_{2}$
Neglecting the transmission and frictional losses, $\mathbf{P}=\mathbf{P}_{1}+\mathbf{P}_{2}$

\subsection{Determination of P1 and P2:}

In order to understand the complex power translations which happens during the wheel-stand, the values of $\mathrm{P}_{1}$ and $\mathrm{P}_{2}$ must be known.

\section{2(a) Determination of $\mathbf{P}_{1}$ :}

Let us again consider a motorbike,

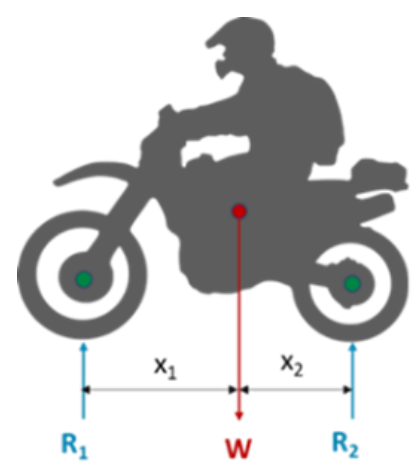

Figure 6. Weight and reaction forces.

Torque required to uplift the bike from front $(\mathrm{T})$ :

$$
\mathrm{T}=\mathrm{Wx}_{2}{ }^{[5]}
$$

Power required to uplift the bike from front $(\mathrm{P})$ :

$$
\mathrm{P}_{1}=\mathrm{T} \omega \quad(\omega=\text { angular velocity })
$$

Substituting Eq. (6) in this,

Since,

$$
\mathrm{P}_{1}=\mathrm{Wx}_{2} \omega
$$

$$
\pi \mathrm{rad}=180^{\circ}
$$

$$
(\pi / 180) \mathrm{rad}=1^{\circ}[4][5]
$$$$
(\pi / 180) \theta \mathrm{rad}=\theta^{\circ}
$$

and,

$$
\begin{aligned}
& \omega=\mathrm{rad} / \mathrm{sec} \\
& \omega=(\pi / 180) \theta \% \mathrm{sec}
\end{aligned}
$$

From Eq. (7) and Eq. (8)

$$
\mathbf{P}_{1}=\mathrm{Wx}_{2}(\boldsymbol{\pi} / \mathbf{1 8 0}) \boldsymbol{\theta}
$$

The value of $\mathrm{x}_{2}$ is a function of $\theta$, as the $\theta$ increases the value of $\mathrm{x}_{2}$ changes as its cosine function.

Moreover,

$$
\mathrm{W}=\mathrm{mg}
$$

Thus, Eq. 9 will become
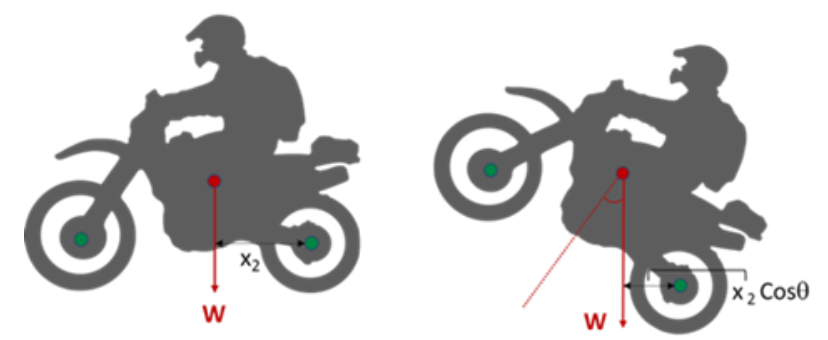

Figure7. Change in distance between weight vector and rear axle with change in angle $\theta$ 


$$
P_{1}=\operatorname{mgx}_{2} \operatorname{Cos} \theta(\pi / 180) \theta
$$

This equation tells us about the power utilization during a wheel-stand at a specific value of $\theta$. But since the value of $\theta$ varies from 0 to maximum tilt angle, the actual value of power utilization could be found out using integration. Integrating $P_{1}$ with respect to small angle $d \theta$,

$$
\begin{aligned}
& \int_{0}^{\theta} \frac{P 1}{d \theta}=\int_{0}^{\theta}\left[\operatorname{mgx} 2 \operatorname{Cos} \theta\left(\frac{\pi}{180}\right) \theta\right] d \theta \\
& \int_{0}^{\theta} \frac{P 1}{d \theta}=\operatorname{mgx} 2\left(\frac{\pi}{180}\right) \int_{0}^{\theta}[\theta \cdot \operatorname{Cos} \theta] d \theta \\
& P 1=\operatorname{mgx} 2\left(\frac{\pi}{180}\right)|\theta \cdot \operatorname{Sin} \theta+\operatorname{Cos} \theta|_{0}^{\theta} \\
& P 1=\operatorname{mgx} 2\left(\frac{\pi}{180}\right)[\theta \cdot \operatorname{Sin} \theta+\operatorname{Cos} \theta-0-1] \\
& P 1=\operatorname{mgx} 2\left(\frac{\pi}{180}\right)[\theta \cdot \operatorname{Sin} \theta+\operatorname{Cos} \theta-1]
\end{aligned}
$$

So, it can be stated that " $A$ rear wheel drive vehicle of mass ' $m$ ' $\mathrm{kg}$ and $C G$ co-ordinate along $X$-axis being ' $x_{2}$ ' meters will need $P_{1}$ watts of power at rear wheel(s) to undergo a wheelie of $\theta$ degrees"

\section{2(b) Determination of $P_{2}$ :}

The power required for forward motion of bike $\left(\mathrm{P}_{2}\right)$ can be calculated using following formula;

Where,

$$
\mathbf{P}_{2}=\operatorname{mav}^{[5][6]}
$$

$\mathrm{m}=$ Mass of vehicle in $\mathrm{kg}$

$\mathrm{a}=$ Acceleration of vehicle in $\mathrm{m} / \mathrm{sec}^{2}$

$\mathrm{v}=$ Velocity of vehicle in $\mathrm{m} / \mathrm{sec}$

$\mathrm{P}_{2}=$ Power required to move the vehicle for the distance of 1 meter for 1 second

\subsection{Factor of power translations (M):}

The complete event of a vehicle undergoing a wheelie can be divided in three time stages:

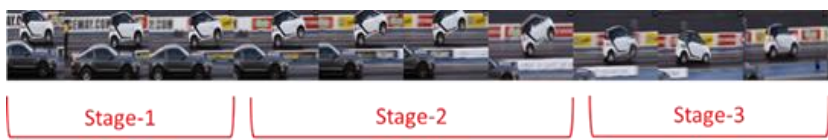

Figure 8. Different time stages of a wheel-stand

\section{Stage-1:}

As soon as the vehicle tends to start off from rest, inertia comes into play and it opposes quick forward motion or acceleration of vehicle. But since very high torque is supplied to rear wheel(s) and in order to form a force equilibrium, the front of the vehicle gets uplifted. In other words, it can be said that while moving from rest, the power supplied by engine gets utilized to undergo a wheelie instead of giving it a straight motion. $\left(\boldsymbol{P}_{1}>\boldsymbol{P}_{2}\right)$

\section{Stage-2:}

When the vehicle reaches the maximum angle of tilt $\left(\theta_{\max }\right)$ while undergoing a wheel-stand, a moment equilibrium is created for a very small time, if a vehicle maintains this equilibrium theoretically it can then wheelie for infinite time but in actual constant acceleration is not possible. So, at $\theta_{\max }$ the power utilized for front lift (P1) and power utilized to increase the momentum (P2) equally contributes to consumption of total power. $\left(\boldsymbol{P}_{1}=\boldsymbol{P}_{2}\right)$

\section{Stage-3:}

After reaching $\theta_{\max }$ the vehicle undergoing the wheelie fails to maintain the moments equilibrium due to insufficient acceleration and as a result of this value of $\theta$ start decreasing and ultimately it reaches 0 , which means the vehicle has be grounded. The decrement of $\theta$ also shows that the distribution of power is uneven. The power utilized to maneuver the vehicle exceeds the power required for a wheelie. $\left(\boldsymbol{P}_{1}<\boldsymbol{P}_{2}\right)$.

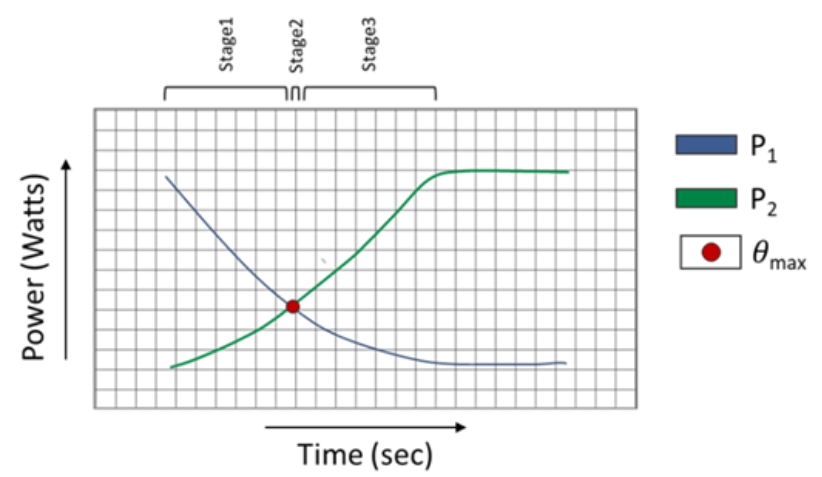

Figure 9. Variation of $\mathrm{P}_{1}$ and $\mathrm{P}_{2}$ with respect to power and time

As we know now, the total power generated by the engine (P) is distributed in $\mathrm{P}_{1}$ and $\mathrm{P}_{2}$. At this stage a question arises, how can we find out how much power is being directed to $\mathrm{P}_{1}$ and $\mathrm{P}_{2}$ at any particular point of time. Because only at $\theta_{\max } \mathrm{P}_{1}$ equates with $\mathrm{P}_{2}$, at all other angles $\mathrm{P}_{1} \neq \mathrm{P}_{2}$.

So, it can be said that at any instant of time,

Where,

$$
\mathbf{P}_{1}=(\mathbf{M}) \mathbf{P}_{2}
$$

\section{$M=$ Factor of power translation.}

Hence

$$
\mathrm{M}=\frac{\mathrm{P} 1}{\mathrm{P} 2}
$$

From Eq. 11 and 12

$$
\begin{aligned}
& \mathrm{M}=\frac{m g x 2\left(\frac{\pi}{180}\right)[\theta \cdot \operatorname{Sin} \theta+\operatorname{Cos} \theta-1]}{\operatorname{mav}} \\
& \mathrm{M}=\frac{g \times 2\left(\frac{\pi}{180}\right)[\theta \cdot \operatorname{Sin} \theta+\operatorname{Cos} \theta-1]}{\mathrm{av}}
\end{aligned}
$$

The value of $\mathrm{M}$ can give us the idea of if the vehicle under consideration will undergo wheelie or not. For those who want to desirably stimulate a wheel-stand, like professional stunt drivers, should make sure that value of $M$ remains close to 1 . On the other hand, those who want to avoid a wheelie for the sake of handling, like drag racers, should make sure that center of mass of the vehicle is away from the rear wheel to prevent wheel-stand under maximum acceleration. ${ }^{[7]}$ 


\section{CONCLUSIONS}

\subsection{After the above discussions and calculations, it has been found that:}

a) In order to undergo a wheelie or wheel stand the torque of the rear wheel must be equivalent to moment generated by weight vector on the center of rear wheel.

b) In case of a two-wheeler, if distance AB between axis of rotation of both wheels is known and the reaction forces $\left(R_{1}\right.$ and $\left.R_{2}\right)$ due to weight of bike and rider are also known the C.G co-ordinates along $\mathrm{X}$-axis will be equal to:

$\boldsymbol{R}_{1} \boldsymbol{A B} /\left(\boldsymbol{R}_{1}+\boldsymbol{R}_{2}\right)$ (Units same as of distance AB).

c) Similarly, if distance $A B$ between axis of rotation of both wheels is known and the reaction forces $\mathrm{R} 1$ and $\mathrm{R} 2$ are also known while the bike is tilted at angle $\theta$. The C.G co-ordinates along Y-axis will be:

$\boldsymbol{F} / \mathrm{Sin} \boldsymbol{\theta}$ (Units same as of distance $\mathrm{AB}$ ).

d) The total power $(\mathrm{P})$ generated by engine is divided into two work streams:

1. Power $\left(\mathbf{P}_{\mathbf{1}}\right)$ utilized in uplifting of vehicle and is equal to: $\left[m g x_{2} \operatorname{Cos} \theta(\pi / 180) \theta\right]$ watts.

2. Power $\left(\mathbf{P}_{2}\right)$ utilized in forward motion of the vehicle and is equal to: $[\text { mav }]^{[1][2]}$ watts.

e) A rear wheel drive vehicle of mass ' $\mathrm{m}$ ' $\mathrm{kg}$ and CG coordinate along $\mathrm{X}$-axis being ' $\mathrm{x} 2$ ' meters will need $\left\{m g x 2\left(\frac{\pi}{180}\right)[\theta \cdot \sin \theta+\cos \theta-1]\right\}$ watts of power at rear wheel(s) to undergo a wheelie of $\theta$ degrees.

f) Percentage of the total engine power consumed in wheelie could be found by $\left(\frac{\mathbf{P 1}}{\mathbf{P 1}+\mathbf{P 2}} \times 100\right)$.

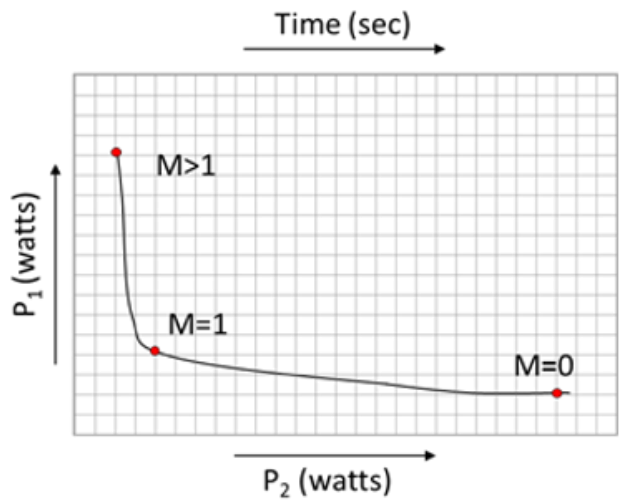

Figure 10. Variation of $M$ with respect to $P_{1} P_{2}$ and time g) The ratio of $\mathbf{P}_{\mathbf{1}}$ and $\mathbf{P}_{\mathbf{2}}$ is known as Factor of power translations (M). The value of $\mathrm{M}$ can give us the idea of if the vehicle under consideration will undergo wheelie or not;

1. If $\mathbf{M}>\mathbf{1}$ : Vehicle will undergo an aggressive wheelie.

2. If $\mathbf{M}<\mathbf{1}$ : Vehicle will not undergo a wheelie.

3. If $\mathbf{M = 1}$ : Vehicle will undergo a wheelie of $\boldsymbol{\theta}$ if accelerated with ' $\mathbf{a}$ ' $\mathrm{m} / \mathrm{sec}^{2}$ to reach the final velocity of ' $\mathbf{v}$ ' $\mathrm{m} / \mathrm{sec}$.

\section{WAY FORWARD}

The objective of this paper is to study about the various forces which stimulate a wheel-stand or a wheelie in a rear wheel drive vehicle. A mathematical indicator (M) has been introduced to predict the rollover of a vehicle during a wheelie. This research could not only contribute to safety for drag racers and stunt but the derived mathematical relations, as an outcome of this research, can also contribute to the field of design and stress analysis of mechanical parts like wheelie bars $^{[8]}$, reducer housing and transmission systems.

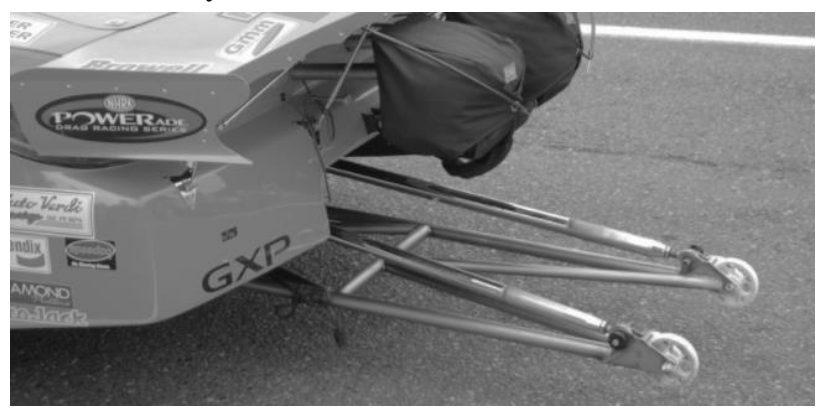

Figure 11. A wheelie bar mounted to chassis of a drag racer.

\section{REFERENCES}

[1] S.S. Rattan (July 1, 2017). Theory of Machines $\left(4^{\text {th }}\right.$ ed.) McGraw-Hill Education.

[2] Birinder Singh (2007) Applied Mechanics ( ${ }^{\text {st }}$ ed.) SK Kat Publication.

[3] N Khurmi \& R S Khurmi (2014) Introduction to Applied Mechanics. S. Chand Publishing.

[4] Willard W. Pulkrabek (2014) Engineering Fundamentals Of The Internal Combustion Engine ( $2^{\text {nd }}$ ed.) Pearson Publication.

[5] John Pearley Huffman (June 2010) "The physics of the wheel stand". Car and driver Retrieved.

[6] C. Ashish (April 21, 2016) "What's the physics behind the wheelie". Scienceabc.com. "

[7] UNSW "Wheelstands or wheelies". Physclips . ש

[8] Gary Grant (July 10, 2012) "This is why drag cars have wheelie bars" Wheels.ca. 투 